\title{
Fertility-sparing management of low-grade endometrial stromal sarcoma: analysis of an institutional series, a population-based analysis and review of the literature
}

\author{
Yawen Zheng, Qihui Yin, Xingsheng Yang, Ruiying Dong \\ Department of Obstetrics and Gynecology, Qilu Hospital, Cheeloo College of Medicine, Shandong University, Jinan, China \\ Contributions: (I) Conception and design: R Dong; (II) Administrative support: R Dong; (III) Provision of study materials or patients: R Dong, X \\ Yang; (IV) Collection and assembly of data: Y Zheng; (V) Data analysis and interpretation: Y Zheng, Q Yin; (VI) Manuscript writing: All authors; (VII) \\ Final approval of manuscript: All authors. \\ Correspondence to: Ruiying Dong. Department of Obstetrics and Gynecology, Qilu Hospital, Cheeloo College of Medicine, Shandong University, 107 \\ Wenhuaxi Road, Jinan, Shandong 250012, China. Email: dongry0709@sina.com.
}

\begin{abstract}
Background: Low-grade endometrial stromal sarcoma (LGESS) is the second most common malignant mesenchymal tumor of the uterus which usually affects young women. However, the researches on the safety and feasibility of the fertility-sparing management of it are limited.

Methods: A retrospective analysis was performed including 5 women diagnosed with LGESS treated with fertility-sparing management at Qilu Hospital of Shandong University from 2010 to 2019. Besides that, 1,070 patients diagnosed with LGESS in SEER database from 1973 to 2016 were examined. By using the KaplanMeier method, survival curves were estimated, and comparisons of statistical significance were performed with the stratified log-rank test within each group.

Results: Five patients with LGESS were enrolled in this study. All patients were submitted to fertilitysparing surgeries, after surgery, they all continued hormonal therapy for one year. Four out of the 5 patients recurred, to be more exact, 3 of them recurred in uterus and the other one in the uterus and iliac vascular region. They all suffered further surgery and all 5 patients were alive at the time of last contact. Besides, among these patients, two conceived naturally and delivered a healthy baby by cesarean section. Among 1,070 patients in SEER database, only $28(2.6 \%)$ patients underwent local tumor excision, including excisional biopsy (39\%), myomectomy (25\%), laser ablation or excision (4\%) and polypectomy (4\%). There was no statistical significance was observed among $\mathrm{TH} \pm \mathrm{BSO}$, radical hysterectomy, subtotal hysterectomy and local tumor excision $(\mathrm{P}=0.29)$.

Conclusions: Our analysis indicated that for those young LGESS patients who wish to preserve their fertility, the feasibility and safety of fertility-sparing management should be considered after gynecological oncologist and gynecological pathologist making professional decisions.
\end{abstract}

Keywords: Low-grade endometrial stromal sarcoma (LGESS); fertility-sparing management; SEER; hormonal therapy; recurrence

Submitted Mar 05, 2020. Accepted for publication Sep 14, 2020.

doi: 10.21037/atm-20-2180

View this article at: http://dx.doi.org/10.21037/atm-20-2180

\section{Introduction}

Endometrial stromal sarcoma (ESS) is a histologic subtype of uterine sarcoma which accounts for approximately $38 \%$ of them (1). It is a rare, indolent uterine malignancy and comprises only $0.2 \%$ of all uterine malignancies (2). In 2014, WHO classification divides ESS into three categories: low-grade ESS (LGESS), high-grade ESS (HGESS), and undifferentiated endometrial sarcoma (3) based on different 
pathologic features.

LGESS is more common than the other two types, in other words, it is the second most common malignant mesenchymal tumor of the uterus (4). It usually affects young women, occasionally occurs in adolescents (5). Those young patients have paid extensive attention on their fertility preservation. LGESS usually exhibits an indolent behavior, nearly $80 \%$ of patients presenting with stage I disease (6) and its 5 -year disease-specific survival (DSS) is approximately $90 \%$ for stages I-II and $50 \%$ for advanced stages (5). No matter which stage the patient was, half of them will recur, and the recurrences are more likely to delayed, the median duration between diagnosis and recurrence was 65 months (6).

Considering that the majority of LGESS express estrogen receptors (ER) and progesterone receptors (PR) (7), the mainstay treatment for LGESS consists of total hysterectomy and bilateral salpingo-oophorectomy (TH/BSO), chemotherapy, radiotherapy and endocrine therapy which might have a role in advanced and recurrent disease $(8,9)$. Taking into account the good oncologic outcomes and the young frequent age at the time of illness, fertility-preserving treatment in young nulliparous females is feasible. However, due to the rarity of this tumor, the experience of fertility-sparing management is very limited (7,10-24).

In this paper, we presented five young LGESS patients who were treated with fertility-sparing surgery and hormonal therapy. Their oncological and pregnancy consequences had been assessed, too. Then we used the Surveillance, Epidemiology, and End Results (SEER database which collects and publishes cancer incidence and survival data from cancer registries covering approximately $28 \%$ of the population of the USA to perform populationbased studies. Finally, we also provided review of the limited literature. We present the following article in accordance with the STROBE reporting checklist (available at http:// dx.doi.org/10.21037/atm-20-2180).

\section{Methods}

\section{Data source}

From 2010 to 2019, from the Gynecologic Oncology Department of Qilu Hospital of Shandong University, five women were enrolled into this study, who was diagnosed with LGESS and desiring to preserve their fertility. This study was conducted in accordance with the Declaration of Helsinki (as revised in 2013). This study was approved by the Institutional Ethics committee of Qilu Hospital (KYLL-2015(KS)-081) and informed consent was taken from all the patients.

Follow-up examinations of all patients were conducted every three months during the first three years after treatment, and every six months thereafter. The follow-ups included the recurrence and survival status, and recurrence was defined as a new focus was found by imaging and confirmed by pathology.

Data from the Surveillance, Epidemiology, and End Results (SEER) database of the National Cancer Institute was used for the analysis. After selecting patients with the corpus uteri as the primary site, LGESS as the histologic type (according to ICD-O-3), we identified 1,070 patients in the analysis between 1973 and 2016. The patients listed in the analysis were staged according to the 7 th edition of the TNM classification of the American Joint Committee on Cancer (AJCC). All data (including public data, radiotherapy and chemotherapy data) used here were permitted, and all variable information was obtained.

\section{Statistical analysis}

Survival curves for overall survival were estimated by the Kaplan-Meier method, and comparisons of statistical significance were performed with the stratified log-rank test within each group. Data was analysed using $\mathrm{R}$ version 3.6.1 (www.r-project.org). All statistical tests were two-sided, with $\mathrm{P}$ values less than 0.05 considered statistically significant. All figures and tables in this article are original.

\section{Results}

Five patients with LGESS were enrolled in this study, the main characteristics of patients and tumors were summarized in Table 1 . The median age was 19.8 years (range, 14-27 years), and at the time of surgery, all of them were nulliparae and expecting pregnancies in the future. Three patients had stage IB cancers, one had stage IIB cancers, and one had stage IIIB cancers.

Two patients were presented with dysmenorrhea, two complained of acute lower abdominal pain, and one reported hypermenorrhea. One patient (case 5) had a surgical history of right breast fibroadenoma resection at 23 years of age, other patients were previously healthy. Before surgery, three patients were presumptively diagnosed as uterine leiomyoma or submucous myoma, one patient was 
Table 1 Main characteristics of LGESS patients

\begin{tabular}{|c|c|c|c|c|c|c|c|c|}
\hline Case \# & Age (years) & $\begin{array}{c}\text { Clinical } \\
\text { presentation }\end{array}$ & $\begin{array}{l}\text { Tumor size on } \\
\text { ultrasound }(\mathrm{cm})\end{array}$ & $\begin{array}{c}\text { Surgical } \\
\text { approach }\end{array}$ & \multicolumn{3}{|c|}{ Immunohistochemical features } & FIGO stage \\
\hline 1 & 27 & Dysmenorrhea & $8.7 \times 6.5$ & THR & $+/+$ & - & + & IB \\
\hline 2 & 15 & Dysmenorrhea & $10.9 \times 10.4$ & THR & $++/++$ & - & + & IIB \\
\hline 3 & 14 & Hypermenorrhea & $6 \times 6$ & LHR & $+/+$ & / & + & IB \\
\hline 5 & 24 & Hypogastralgia & $6.1 \times 5.2$ & $\mathrm{HR}+\mathrm{THR}$ & $+++/+++$ & + & + & IB \\
\hline
\end{tabular}

HR, hysteroscopy resection; THR, transabdominal hysteromyoma resection; LHR, laparoscope hysteromyoma resection; ER, estrogen receptors; PR, progesterone receptors.

Table 2 Adjuvant hormonal treatments and outcomes of LGESS patients

\begin{tabular}{|c|c|c|c|c|c|c|c|c|}
\hline Case \# & Adjuvant HT & $\begin{array}{l}\text { HT duration } \\
\text { (months) }\end{array}$ & Pregnancy & $\begin{array}{l}\text { Obstetric } \\
\text { outcomes }\end{array}$ & Recurrence & $\begin{array}{c}\text { RFS } \\
\text { (months) }\end{array}$ & $\begin{array}{l}\text { Treatment of } \\
\text { recurrence }\end{array}$ & $\begin{array}{l}\text { Current sta- } \\
\text { tus }\end{array}$ \\
\hline 1 & $\begin{array}{l}\text { MPA } 500 \mathrm{mg} / \text { day } \\
\text { and } \mathrm{GnRHa} \\
3.75 \mathrm{mg} / 4 \text { weeks }\end{array}$ & 12 and 6 & No & / & Yes & 22 & TH/BSO & NED \\
\hline 2 & MPA 500 mg/day & 12 & No & / & Yes & 31 & $\begin{array}{c}\text { MPA } 500 \mathrm{mg} / \\
\text { day and } \mathrm{GnRHa}\end{array}$ & Recurrence \\
\hline 4 & MPA 250 mg/day & 12 & Yes & NFTD & Yes & 56 & TH/BSO & NED \\
\hline 5 & MPA 250 mg/day & 12 & Yes & NFTD & Yes & 45 & $\mathrm{TH} / \mathrm{BSO}+\mathrm{CRS}$ & NED \\
\hline
\end{tabular}

HT, hormonal treatment; LG-ESS, low-grade endometrial stromal sarcoma; MPA, medroxyprogesterone acetate; GnRHa, gonadotrophinreleasing hormone analogues; RFS, recurrence-free survival; TH/BSO, total hysterectomy and bilateral salpingo-oophorectomy; NED, no evidence of disease.

diagnosed as degeneration of uterine fibroids, and the other patient was recognized as "pelvic mass". For all patients, the previous B ultrasound examination demonstrated a hypoechoic lesion larger than $5 \mathrm{~cm}$. Two patients underwent laparotomy, one patient underwent laparoscopy, one patient (case 4) beard laparoscopic exploration and then transferred to laparotomy because of severe adhesion and the patient's desire to preserve fertility (12), and the other patient (case 5) suffered hysteroscopy first and then laparotomy because of the histological results and incomplete resection (13). No perioperative complications occurred. $\mathrm{PR}$ and $\mathrm{ER}$ was positive in all cases.

According to the hormone receptor status, adjuvant hormonal treatment was administered to all patients immediately after the fertility-sparing surgery. The adjuvant hormonal treatment and reproductive outcomes are demonstrated in Table 2. Three patients used medroxyprogesterone acetate (MPA), one patient used megestrol acetate (MA), the remaining one patient received
MPA and gonadotrophin-releasing hormone ( $\mathrm{GnRH})$ analogues. Hormonal therapy was well tolerated among all patients and they all continued hormonal therapy for one year.

After surgery, all patients were followed up regularly. Four patients recurred and the median recurrence-free survival time was 38 months (range, 22-54 months) (Table 2). Among them, the recurrence in three patients was limited to the uterus, two of them underwent TH/BSO with no evidence of disease at the time of last contact, the other one (case 2) underwent adjuvant hormonal therapy again because of young age, while after treatment, the tumor did not continue to grow. One patient (case 5) experienced recurrence in the uterus and iliac vascular region in pelvic 45 months after fertility-sparing surgery, she later suffered TH/BSO and cytoreductive surgery with no evidence of disease at the time of last contact. Only one patient (case 3) with stage IB tumor did not relapse during 74 months follow-up. All 5 patients were still alive at the 


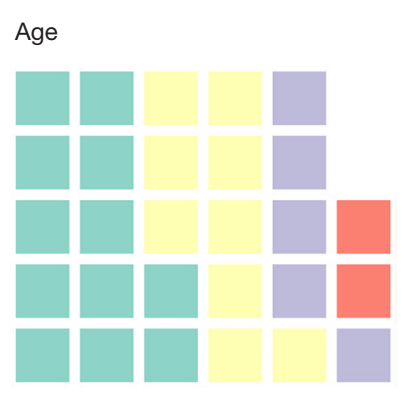

Age 20-39 ( $n=12,43 \%)$

Age 40-59 ( $n=9,32 \%)$

Age 60-79 $(n=5,18 \%)$

Ages $80+(n=2,7 \%)$

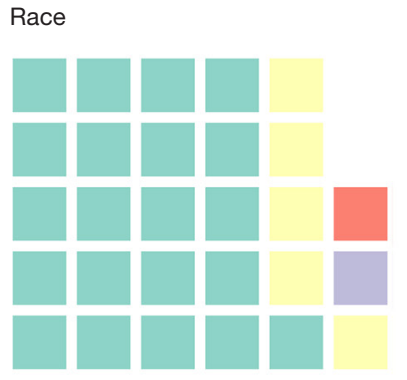

AJCC stage 7th

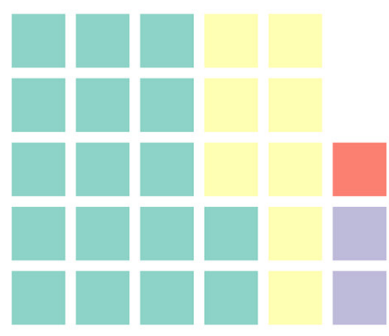

Grade II (n=18,64.0\%)

NOS $(n=6,21.0 \%)$

Grade I $(n=4,14.0 \%)$
N.A. $(n=15,54 \%)$

5-10cm ( $\mathrm{n}=5,18 \%)$

$\leq 5 \mathrm{~cm}(\mathrm{n}=4,14 \%)$

$10-20 \mathrm{~cm}(\mathrm{n}=4,14 \%)$
Surgery

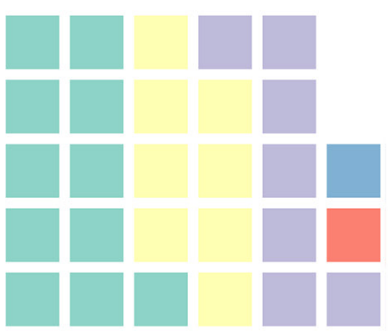

White $(n=21,75 \%)$

Black $(n=5,18 \%)$

Asian $(n=1,4 \%)$

Indian $(n=1,4 \%)$
N.A, $(n=17,61.0 \%)$

Stage I $(n=8,29.0 \%)$

Stage II $(n=2,7.0 \%)$

Stage IV $(n=1,4.0 \%)$
Excisional_biopsy $(\mathrm{n}=11,39 \%)$

Tumor_excision_NOS ( $n=8,29 \%)$

Myomectomy ( $n=7,25 \%)$

Laser_ablation_or_excision $(n=1,4 \%)$

Polypectomy ( $n=1,4 \%)$

Figure 1 The characteristics of LGESS patients who underwent local tumor excision from SEER database.

time of last contact.

It's worth noticing that among these patients who attempted pregnancy, two conceived naturally and delivered a healthy baby by cesarean section. The durations between treatment and pregnancy was 42 months (case 4) and 22 months (case 5). No evidence showed that recurrences occurred during pregnancy, one patient (case 4) relapsed four months after cesarean delivery and underwent TH/ $\mathrm{BSO}$, the other patient (case 5) relapsed about one year after delivery and underwent TH/BSO and cytoreductive surgery.

In SEER database, a total of 1,070 women with LGESS were identified, among them, only 28 (2.6\%) patients underwent local tumor excision, the surgical procedures of these patients include excisional biopsy (39\%), myomectomy
(25\%), laser ablation or excision (4\%) and polypectomy (4\%). The characteristics of these patients are presented in Figure 1. Most of them (43\%) were in reproductive age, the median age was 42.5 years (range, 23-88). The majority were White $(75 \%)$ race, followed by Black (18\%) and Asian (4\%). Tumor cell grade was available in 22 patients $(79 \%)$, 4 being grade $1(14 \%)$ and 18 being grade $2(64 \%)$. The information about tumor size and stage was missing for most patients. Among patients who had this record, 4 (14\%) had tumors smaller than $5 \mathrm{~cm}, 5(18 \%)$ had tumors between 5 and $10 \mathrm{~cm}$, and $4(14 \%)$ had tumors larger than $10 \mathrm{~cm}$. As for stage, $8(29 \%)$ patients were stage I, $2(7 \%)$ were stage II, and $1(4 \%)$ was stage IV. Furthermore, we found that one patient suffered diffuse large B cell lymphoma two years after surgery, and one patient had a history of adenoid cystic 
A

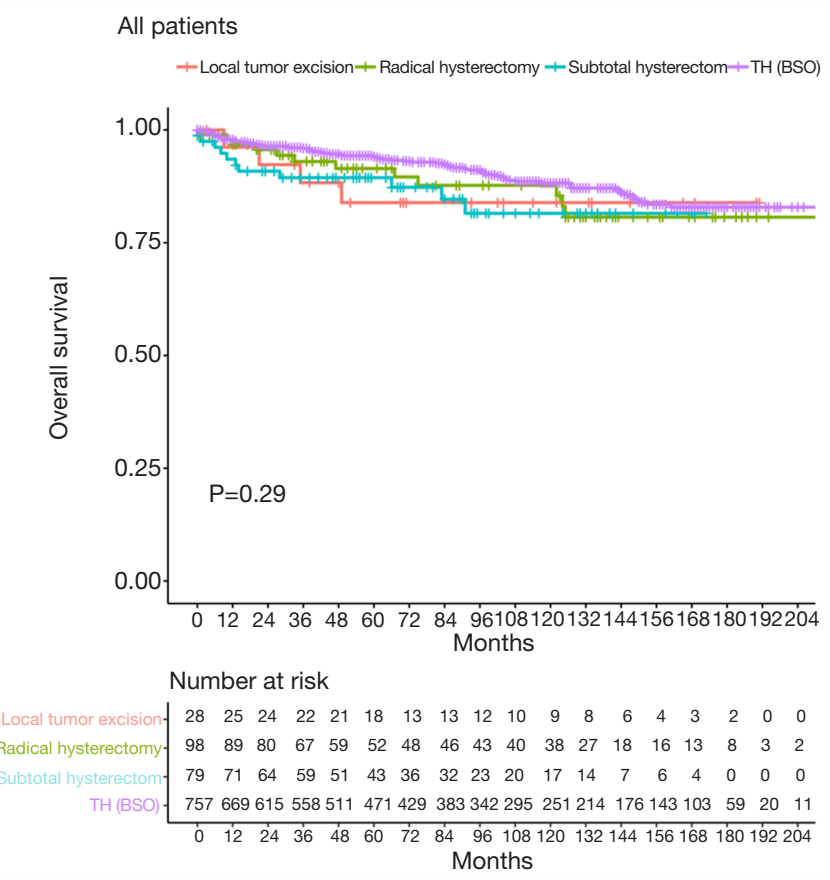

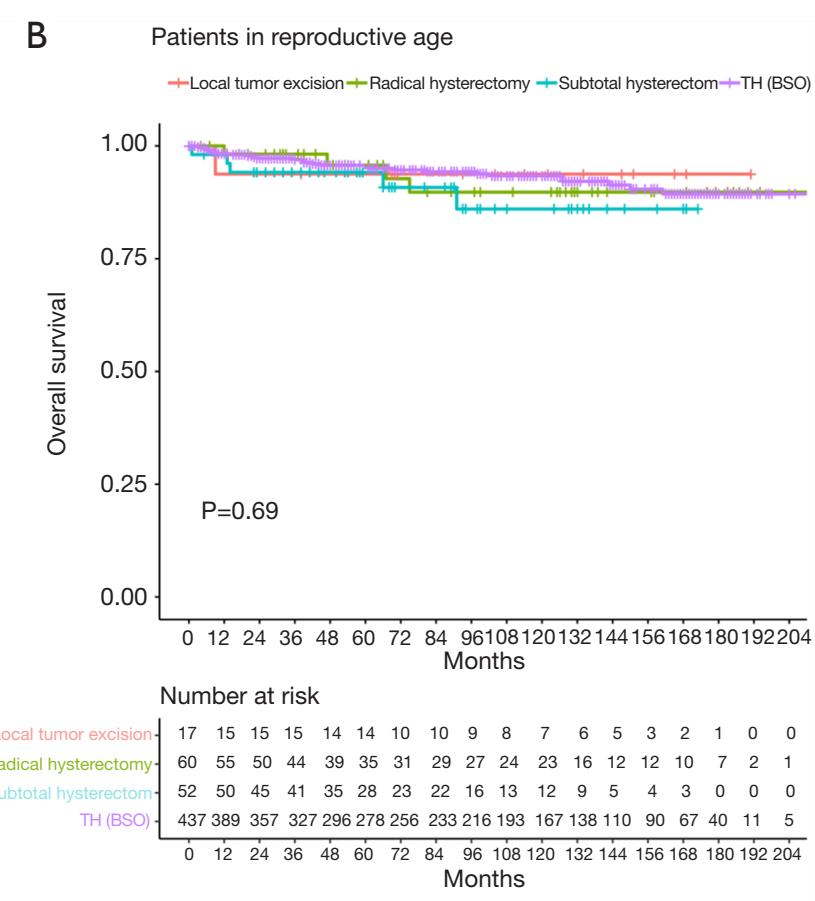

Figure 2 Survival curves for overall survival by different surgical procedure in all LGESS patients (A) and patients of child-bearing age (15-49 years old) (B) from SEER database.

carcinoma of the breast.

The median follow-up time was 84.5 months (range, $1-475$ months), we provided the Kaplan-Meier survival time of different surgical procedure among all LGESS patients, and the results showed that, no statistical significance was observed among $\mathrm{TH} \pm \mathrm{BSO}$, radical hysterectomy, subtotal hysterectomy and local tumor excision $(\mathrm{P}=0.29)$ (Figure $2 A)$. Besides, considering that most patients who chose fertilitysparing surgery were in child-bearing age (15-49 years old), we performed Kaplan-Meier survival analysis among these patients and the results showed that, local tumor excision did not affect the probability of survival $(\mathrm{P}=0.69)$ (Figure 2B).

\section{Discussion}

ESS is a kind of rare malignant tumor which originates in the endometrial stromal, and comprises three different subtypes (3). Unlike HGESS and undifferentiated endometrial sarcoma, which are more destructive, LGESS is indolent and characterized by delayed recurrence. For patients with stage I LGESS, 5-year DSS has been estimated to be $90 \%$ (5) and the median time of recurrence is 65 months (6).
The common clinical manifestation is abnormal vaginal bleeding. Two patients in our series were presented with acute hypogastralgia as the initial symptom, this might be due to the large tumor size. Due to the nonspecific symptoms, the proper preoperative diagnosis is difficult, usually, it could be thought as uterine leiomyoma or adenomyosis (25). Because LGESS could invade the myometrium and show an infiltrative growth pattern, chest CT and abdomen-pelvis CT or MR might help in tumor staging and treatment options (26). But the diagnosis can only be made according to the pathological results. Microscopically, LGESS comprises cells resembling endometrial stroma proliferative phase and lacks significant cytological atypia. What's more, CD10, SMA, desmin and ER/PR could be used as immunohistochemical markers for diagnosis (27), however, these markers are still nonspecific because their interpretation focuses on the degree of positivity rather than just positivity (3).

The main treatment for LGESS includes TH and BSO, but considering its hormone-sensitive character, favorable prognosis and indolent course, fertility-sparing management could be deliberated for those young patients who desire child-bearing in the future. The management usually includes conservative resection of a uterine mass 
and adjuvant hormonal therapy. Through analysis of SEER database, we found that no matter in all patients or only in patients of child-bearing age, there were no statistical significance observed among $\mathrm{TH} \pm \mathrm{BSO}$, radical hysterectomy, subtotal hysterectomy and local tumor excision, which indicated the feasibility and safety of fertility-sparing management. However, because of the rarity of this tumor, the experience of fertility-sparing management is very limited (mostly based on case reports) (7,10-24).

In order to further observing the feasibility of fertilitysparing management, we summarized 14 literature, including 40 cases of conservative treatment (Table 3). Eight literatures reported cases of LGESS patients who experienced a successful pregnancy following fertilitypreserving treatment $(10,11,13-15,17-19)$, three patients were not treated with adjuvant therapy after surgery, one of them recurred at peritoneum 16 months later and was treated with letrozole (15), one patient found recurrence 1 year after surgery with pregnancy (14), and the other patient did not relapse and was 11 weeks of gestation at the time of last contact (17). One patient suffered ifosfamide for 4 cycles, combined with MPA $250 \mathrm{mg}$ for 7 months, and there were no signs of tumor recurrence in 47 months (19). In the remaining four patients, two received MA for at least 6 months $(11,18)$, one used MPA $250 \mathrm{mg}$ for 6 months (13), and the other one received Letrozole $2.5 \mathrm{mg}$ for 6 months (10). Moreover, some literature including more than one patient also came to the conclusion that fertility-sparing surgery may be considered for young patients with early stage LGESS who wish to preserve their fertility $(7,23,24)$. A retrospectively study (24) found that two patients were treated with GnRH analogues followed by LNG-IUD and no recurrence occurred, that indicate that LNG-IUD and GnRH analogues might be a promising treatment for patients who don't want to conceive in the short-term.

Although most of the literature focused on stage I and II patients, in our series, one patient with stage IIIB (case 4) still got pregnant after conservative treatment. It has to be said that this was a relatively rare case with serious risks. Most studies believe that the treatment outcome has a significant association with stage, histological subtype, tumor size and positivity from cytologic biopsy (28). Although some patients in our series (case 4,5$)$ and in literature $(15,16,18)$ relapsed after pregnancy, it's hard to say that pregnancy may contribute to the development of LGESS due to changes in hormone

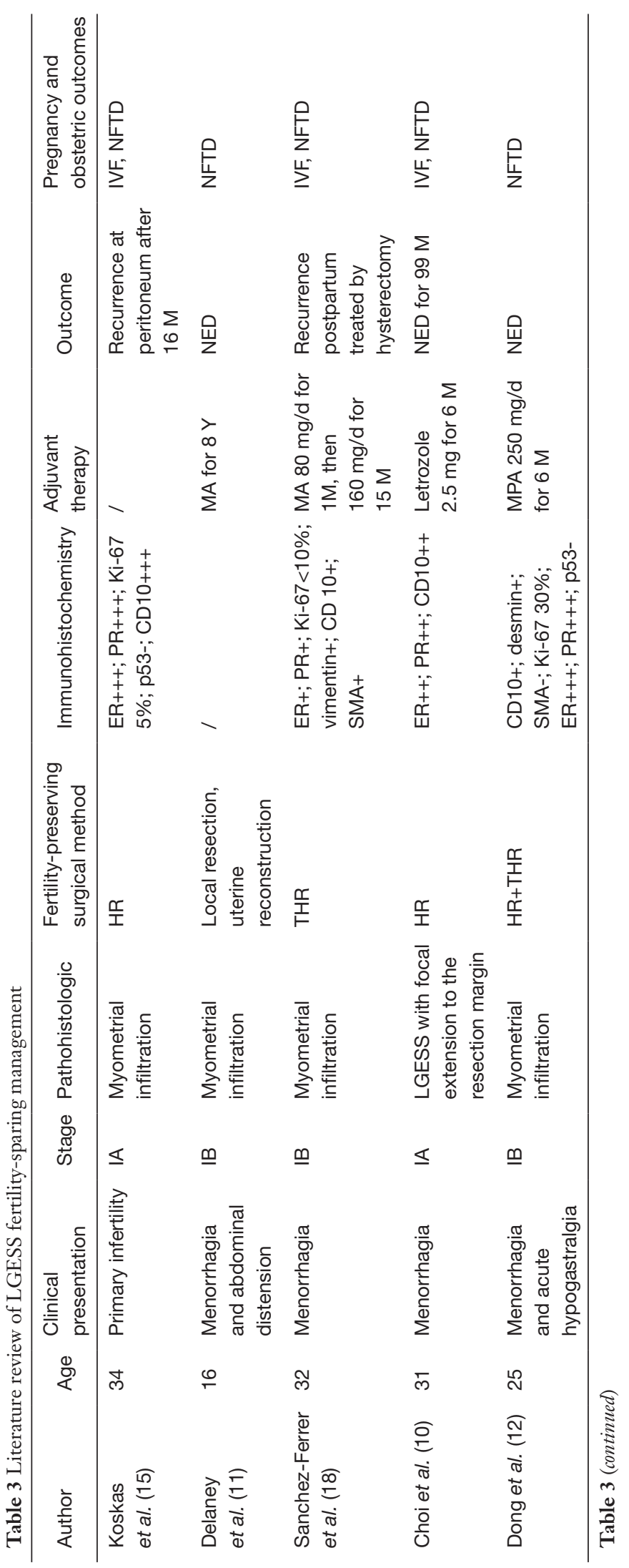




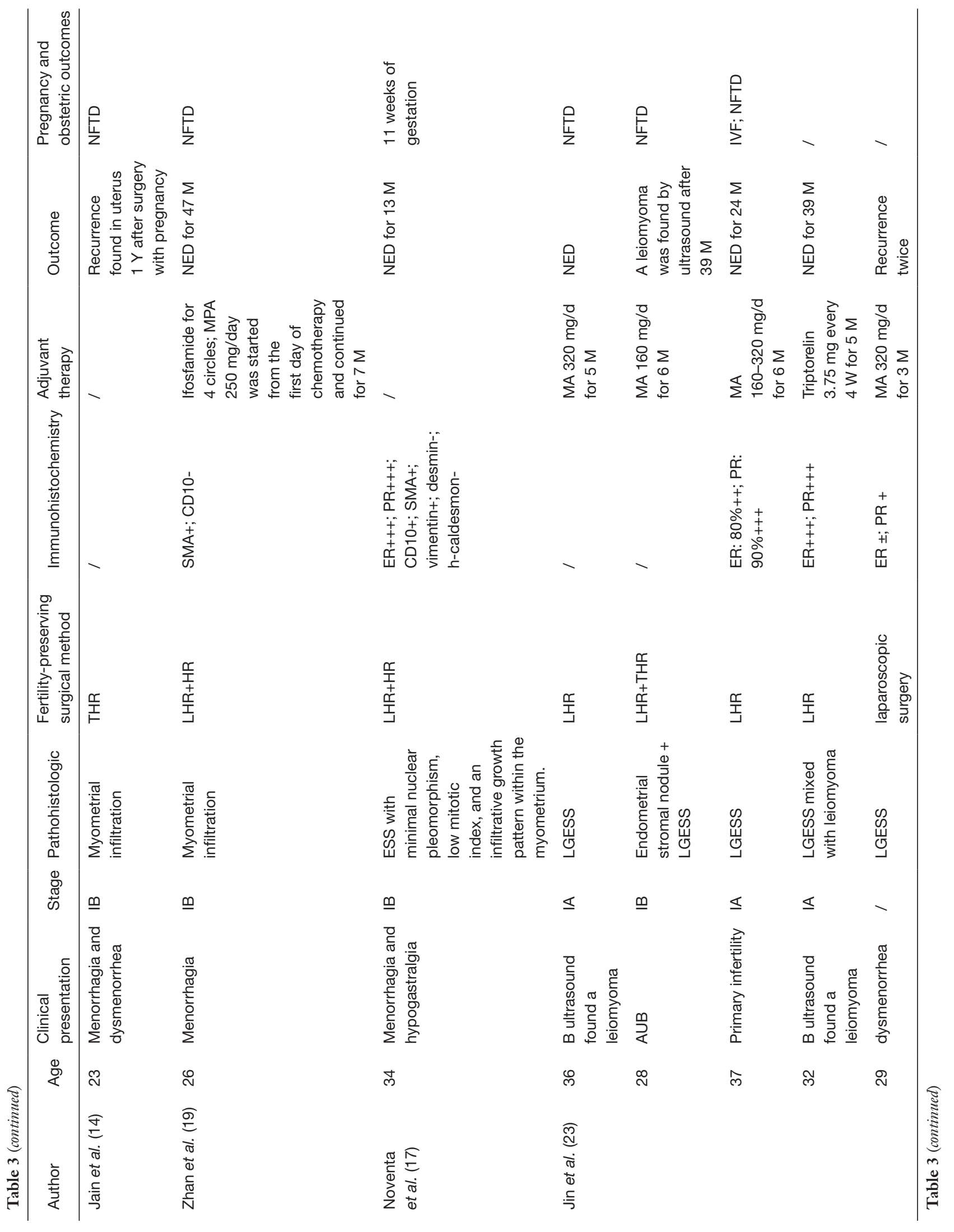




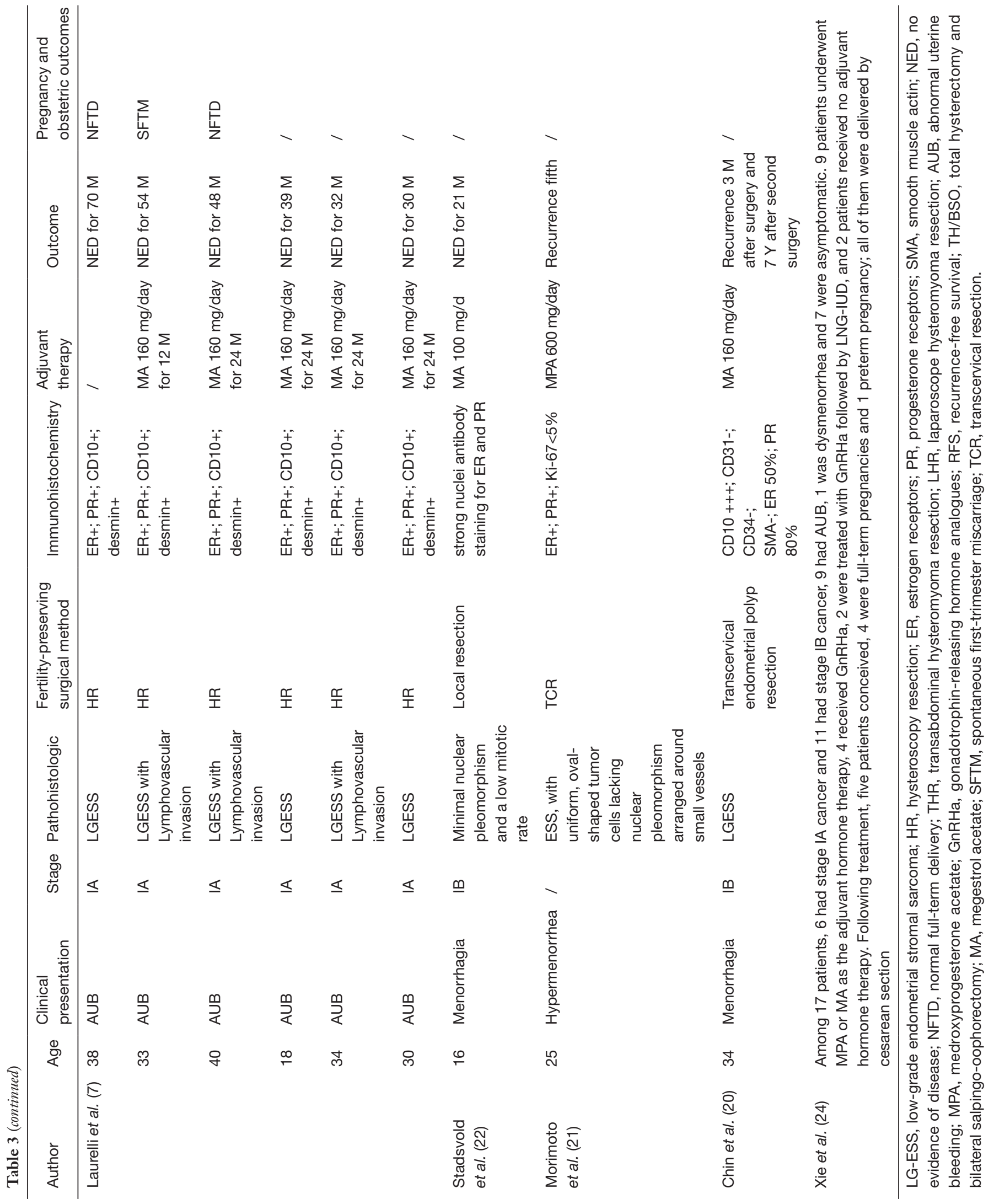


levels during pregnancy. Nevertheless, this reminded us gynaecologists that we should consider preserve fertility and undergo pregnancy when making decisions.

In conclusion, although fertility-sparing management is not the current standard of treatment for young LGESS patients, it might be considered by those who desire to preserve their reproductive potential. But it needs gynecological oncologist and gynecological pathologist to make the professional decision, besides, patients should be counseled about the oncologic risks associated with deviation from the standard of care. Despite the fact that the analysis of SEER shows that fertility-sparing management is safe, large-scale studies with long-term follow-up are still needed to confirm the results as well as to further assess the safety and feasibility of conservative excision of uterine mass combined with adjuvant hormonal therapy.

\section{Acknowledgments}

Funding: None.

\section{Footnote}

Reporting Checklist: The authors have completed the STROBE reporting checklist. Available at http://dx.doi. org/10.21037/atm-20-2180

Data Sharing Statement: Available at http://dx.doi. org/10.21037/atm-20-2180

Peer Review File: Available at http://dx.doi.org/10.21037/ atm-20-2180

Conflicts of Interest: All authors have completed the ICMJE uniform disclosure form (available at http://dx.doi. org/10.21037/atm-20-2180). The authors have no conflicts of interest to declare.

Ethical Statement: The authors are accountable for all aspects of the work in ensuring that questions related to the accuracy or integrity of any part of the work are appropriately investigated and resolved. This study was conducted in accordance with the Declaration of Helsinki (as revised in 2013). This study was approved by the Institutional Ethics committee of Qilu Hospital (KYLL-2015(KS)-081) and informed consent was taken from all the patients.

Open Access Statement: This is an Open Access article distributed in accordance with the Creative Commons Attribution-NonCommercial-NoDerivs 4.0 International License (CC BY-NC-ND 4.0), which permits the noncommercial replication and distribution of the article with the strict proviso that no changes or edits are made and the original work is properly cited (including links to both the formal publication through the relevant DOI and the license). See: https://creativecommons.org/licenses/by-nc-nd/4.0/.

\section{References}

1. Yang H, Li XC, Yao C, et al. Proportion of uterine malignant tumors in patients with laparoscopic myomectomy: a national multicenter study in China. Chin Med J (Engl) 2017;130:2661.

2. Tropé CG, Abeler VM, Kristensen GB. Diagnosis and treatment of sarcoma of the uterus. A review. Acta Oncol 2012;51:694-705.

3. Oliva E, Carcangiu M, Carinelli S, et al. Mesenchymal tumours. WHO classification of Tumours of female reproductive organs. Fourth Edition 2014:135-41.

4. Ali RH, Rouzbahman M. Endometrial stromal tumours revisited: an update based on the 2014 WHO classification. J Clin Pathol 2015;68:325-32.

5. Bai H, Yang J, Cao D, et al. Ovary and uterus-sparing procedures for low-grade endometrial stromal sarcoma: a retrospective study of 153 cases. Gynecol Oncol 2014;132:654-60.

6. Stewart L, Beck T, Giannakopoulos N, et al. Impact of oophorectomy and hormone suppression in low grade endometrial stromal sarcoma: A multicenter review. Gynecol Oncol 2018;149:297-300.

7. Laurelli G, Falcone F, Scaffa C, et al. Fertilitysparing management of low-grade endometrial stromal sarcoma: analysis of an institutional series and review of the literature. Eur J Obstet Gynecol Reprod Biol 2015;195:61-6.

8. Lucas R, Cunha TM. Uterine sarcomas. MRI and CT of the Female Pelvis. Springer, 2016:209-24. Available online: https://link.springer.com/chapter/10.1007/174_2016_90

9. Seagle BLL, Shilpi A, Buchanan S, et al. Low-grade and high-grade endometrial stromal sarcoma: A National Cancer Database study. Gynecol Oncol 2017;146:254-62.

10. Choi MC, Kim G, Hwang YY. Fertility-sparing management combined with photodynamic therapy for endometrial stromal sarcoma: A case report. Photodiagnosis Photodyn Ther 2014;11:533-6.

11. Delaney AA, Gubbels AL, Remmenga S, et al. Successful 
pregnancy after fertility-sparing local resection and uterine reconstruction for low-grade endometrial stromal sarcoma. Obstet Gynecol 2012;120:486-9.

12. Dong R, Mao H, Zhang P. Conservative management of endometrial stromal sarcoma at stage III: A case report. Oncol Lett 2014;8:1234-6.

13. Dong R, Pang Y, Mao H, et al. Successful pregnancy following conservative management of low-grade endometrial stromal sarcoma: A case report. Oncol Lett 2014;7:1039-42.

14. Jain PS, Jariwala MC. Successful Pregnancy with Endometrial Stromal Sarcoma (ESS). J Obstet Gynaecol India 2014;64:297-8.

15. Koskas M, Morice P, Yazbeck C, et al. Conservative management of low-grade endometrial stromal sarcoma followed by pregnancy and severe recurrence. Anticancer Res 2009;29:4147-50.

16. Maeda O, Moritani S, Ichihara S, et al. Long-term survival in low-grade endometrial stromal sarcoma with childbirth and multidisciplinary treatment: a case report. J Med Case Rep 2015;9:233.

17. Noventa M, Gizzo S, Conte L, et al. Fertility sparing surgery in young women affected by endometrial stromal sarcoma: an oncologic dilemma or a reliable option? review of literature starting from a peculiar case. Onco Targets Ther 2015;8:29-35.

18. Sanchez-Ferrer ML, Machado-Linde F, Ferri-Niguez B, et al. Reproductive outcome after uterine-sparing surgery for endometrial stromal sarcoma. Gynecol Oncol Case Rep 2012;3:4-6.

19. Zhan R, Wen H, Gao X, et al. Successful term pregnancy after laparoscopic surgery of low grade endometrial

Cite this article as: Zheng Y, Yin Q, Yang X, Dong R. Fertility-sparing management of low-grade endometrial stromal sarcoma: analysis of an institutional series, a populationbased analysis and review of the literature. Ann Transl Med 2020;8(21):1358. doi: 10.21037/atm-20-2180 stromal sarcoma. Chin Med J (Engl) 2014;127:391-2.

20. Chin TH, Lin G, Wu RC, et al. Recurrence after fertilitypreserving surgery for low-grade endometrial stromal sarcoma. J Obstet Gynaecol Res 2018;44:1836-42.

21. Morimoto A, Tsubamoto H, Inoue K, et al. Fatal case of multiple recurrences of endometrial stromal sarcoma after fertility-sparing management. J Obstet Gynaecol Res 2015;41:162-6.

22. Stadsvold JL, Molpus KL, Baker JJ, et al. Conservative management of a myxoid endometrial stromal sarcoma in a 16-year-old nulliparous woman. Gynecol Oncol 2005;99:243-5.

23. Jin Y, Li Y, Deng CY, et al. Fertility-sparing treatment of low-grade endometrial stromal sarcoma. Int J Clin Exp Med 2015;8:5818-21.

24. Xie W, Cao D, Yang J, et al. Fertility-sparing surgery for patients with low-grade endometrial stromal sarcoma. Oncotarget 2017;8:10602-8.

25. Park JY, Park SK, Kim DY, et al. The impact of tumor morcellation during surgery on the prognosis of patients with apparently early uterine leiomyosarcoma. Gynecol Oncol 2011;122:255-9.

26. Group EESNW. Soft tissue and visceral sarcomas: ESMO Clinical Practice Guidelines for diagnosis, treatment and follow-up. Ann Oncol 2014;25:iii102-iii12.

27. Conklin CM, Longacre TA. Endometrial stromal tumors: the new WHO classification. Adv Anat Pathol 2014;21:383-93.

28. Yalman D, Ozsaran Z, Baltalarli B, et al. Results of postoperative radiotherapy in the treatment of uterine sarcomas: a retrospective analysis of 46 patients. Eur J Gynaecol Oncol 2008;29:46-51. 